\title{
Effects of Sodium Chloride on Steady-state Growth and Metabolism of Saccharomyces cerevisiae
}

\author{
By T. G. WATSON* \\ Laboratory of Microbiology, Gulbenkian Institute of Science, \\ Oeiras, Portugal
}

(Accepted for publication 25 September 1970)

SUMMARY

Sodium chloride decreased the maximum specific growth rate of Saccharomyces cerevisiae. Chemostat experiments showed this to be largely due to an increased requirement for energy-yielding substrate, apparently linked to maintenance and leading to a decrease in the yield. The increased maintenance requirement is probably concerned with maintaining an intracellular $\mathrm{Na}^{+}$concentration ten times lower than the extracellular concentration. $\mathrm{NaCl}$ caused much higher concentrations of glucose to be required to maintain any particular glucose-uptake rate; it also increased the production of glycerol.

\section{INTRODUCTION}

Sodium chloride affects many parameters of yeast growth, including growth rate (Norkrans, 1966; Combs, Guarneri \& Pisano, 1968), yield of biomass (Ross \& Morris, 1962; Norkrans, I966; Combs et al. 1968), lag phase of growth (Phaff, Mrak \& Williams, 1952; Ross \& Morris, 1962; Norkrans, 1966) and cell composition (Combs et al. 1968). The tolerance of various yeast species to $\mathrm{NaCl}$ varies greatly (Phaff et al. 1952; Ross \& Morris, 1962; Norkrans, 1968; van Uden \& Buckley, 1970; van Uden \& Vidal-Leiria, 1970). The two most important factors appear to be the presence of a mechanism for retaining a low concentration of $\mathrm{NaCl}$ within the organism (Norkrans \& Kylin, 1969) and the ability of enzymes to operate in the presence of high concentrations of $\mathrm{NaCl}$ (Ingram, 1957). The present paper is an attempt to interpret various effects of $\mathrm{NaCl}$ on growth of Saccharomyces cerevisiae in the chemostat through an analysis of growth kinetics and energetics.

\section{METHODS}

Organisms used were Saccharomyces cerevisiae IGC 3507 from the culture collection of this laboratory and a respiratory-deficient mutant of it. Experiments were carried out using the mutant unless otherwise indicated in the text. The mutant was chosen to eliminate effects due to variation in respiratory quotient with either change in dilution rate or presence of $\mathrm{NaCl}$ and thus to facilitate the computation of yield and maintenance parameters.

* Present address: National Chemical Research Laboratory, Council for Scientific and Industrial Research, P.O. Box 395, Pretoria, Republic of South Africa. 
Growth conditions. Cultures were grown in a chemostat at $20^{\circ}$ (Watson, 1969). The culture medium was similar to that used by van Uden (I967a) except that $\mathrm{I} \%(\mathrm{w} / \mathrm{v})$ glucose and in certain experiments $\mathrm{I} \cdot \mathrm{O} \mathrm{M}-\mathrm{NaCl}$ were used. Under these conditions the cultures were carbon-limited. Samples of culture containing approximately $20 \mathrm{mg}$. dry wt organisms were filtered through preweighed filters $(\mathrm{I} \cdot 2 \mu \mathrm{m}$. pore size; Millipore Filter Corporation, Bedford, Massachusetts). The filters were washed with three volumes of distilled water and dried to constant weight at $80^{\circ}$.

Determination of glucose and glycerol. Samples of culture were rapidly filtered through a Millipore membrane. Glucose and glycerol in the filtrates were estimated by the glucose oxidase and glycerol kinase methods (Biochemica Test Combinations, Boehringer Mannheim GmbH).

Production of carbon dioxide by cultures was measured using an infrared carbon dioxide analyser (M.S.A. Lira Infrared Analyser Model 300; Mine Safety Appliances Company, Glasgow; Watson, 1969).

Sodium and potassium contents of organisms. A portion of culture containing approximately $40 \mathrm{mg}$. dry wt of organisms was rapidly filtered and washed with $5 \times 10 \mathrm{ml}$. of 0. I M- $\mathrm{MgCl}_{2}$ (pH 6.0 to 6.5; Tempest, Dicks \& Hunter, 1966). The filter was placed in approximately $7 \mathrm{ml}$. of de-ionized water and boiled for $10 \mathrm{~min}$. The suspension was centrifuged, washed with a small volume of de-ionized water, recentrifuged and the combined extracts made up to Io ml. with de-ionized water. Analyses of $\mathrm{Na}^{+}$and $\mathrm{K}^{+}$ were carried out using an atomic absorption Spectrometer (Perkin-Elmer Model 290, Perkin-Elmer Corp., Norwalk, Connecticut).

\section{Effect of $\mathrm{NaCl}$ on yeast growth}

\section{RESULTS}

In batch cultures of the yeast, the maximum specific growth rate $(\mu)_{\max }$ and the yield with respect to glucose $\left(Y^{G}\right)$ but not the rate of glucose uptake decreased with 0.25 to $\mathrm{I} \cdot 50 \mathrm{M}-\mathrm{NaCl}$. An extension in the duration of the lag phase of growth was also observed. Subsequent experiments were carried out in the chemostat under conditions, of glucose limitation.

Pirt (1965) derived the following equation relating yield $(Y)$, maximum yield $\left(Y_{\max }\right)$, specific uptake rate of energy-yielding substrate specifically for maintenance $\left(k_{\mathrm{m}}\right)$, and specific growth rate $(\mu)$

$$
\frac{\mathrm{I}}{Y}=\frac{\mathrm{I}}{Y_{\max }}+\frac{k_{\mathrm{m}}}{\mu}
$$

If $Y_{\max }$ and $k_{\mathrm{m}}$ are invariant with $\mu$, a plot of $\mathrm{I} / Y$ against $\mathrm{I} / \mu$ will give a straight line with slope $k_{\mathrm{m}}$ and intercept on the ' $y$ ' axis of $\mathrm{I} / Y_{\max }$. Fig. I shows such a plot for chemostat cultures grown in the presence and absence of $\mathrm{NaCl}$. A glucose-limited culture without $\mathrm{NaCl}$ showed a small increase in yield with increase in dilution rate as predicted by equation (I). Deviation from linearity occurred at high dilution rates; a $k_{\mathrm{m}}$ value of approximately $0.2 \mu$ mole glucose $/ \mathrm{mg}$. dry wt $/ \mathrm{h}$. was calculated from the linear part. A glucose-limited culture grown in the presence of $\mathrm{I} \cdot \mathrm{O} \mathrm{M}-\mathrm{NaCl}$ showed still less linearity in this plot, but a very pronounced decrease was obtained in the yield following a decrease in dilution rate, indicating a high maintenance requirement of approximately $2 \mu$ moles glucose $/ \mathrm{mg}$. $/ \mathrm{h}$. 


\section{Effect of $\mathrm{NaCl}$ on energy metabolism}

As pointed out by van Uden (1968), concepts of maintenance and yield may also be applied to the products of energy metabolism. Fig. 2 shows results for the evolution of $\mathrm{CO}_{2}$. The approximate $k_{\mathrm{m}}$ values obtained were, without $\mathrm{NaCl}, 0.4 \mu$ mole $\mathrm{CO}_{2} / \mathrm{mg}$. $/ \mathrm{h}$., and with $\mathrm{NaCl}, 2 \cdot 0 \mu$ moles $\mathrm{CO}_{2} / \mathrm{mg}$. $/ \mathrm{h}$. Since the ratio of the $k_{\mathrm{m}}$ values gives the direct stoichiometry for the net conversion of energy substrate during maintenance without growth, the ratio $k_{\mathrm{m}}$ glucose: $k_{\mathrm{m}} \mathrm{CO}_{2}$ of $\mathrm{I}: 2$ obtained for the culture lacking $\mathrm{NaCl}$ suggests the conversion of I mole of glucose to 2 moles of $\mathrm{CO}_{2}$. The stoichiometry for the culture containing $\mathrm{NaCl}$ was $\mathrm{I}$ mole of glucose producing I mole of $\mathrm{CO}_{2}$ and suggested incomplete fermentation of substrate for maintenance, due to the production of end products in addition to $\mathrm{CO}_{2}$ and ethanol.

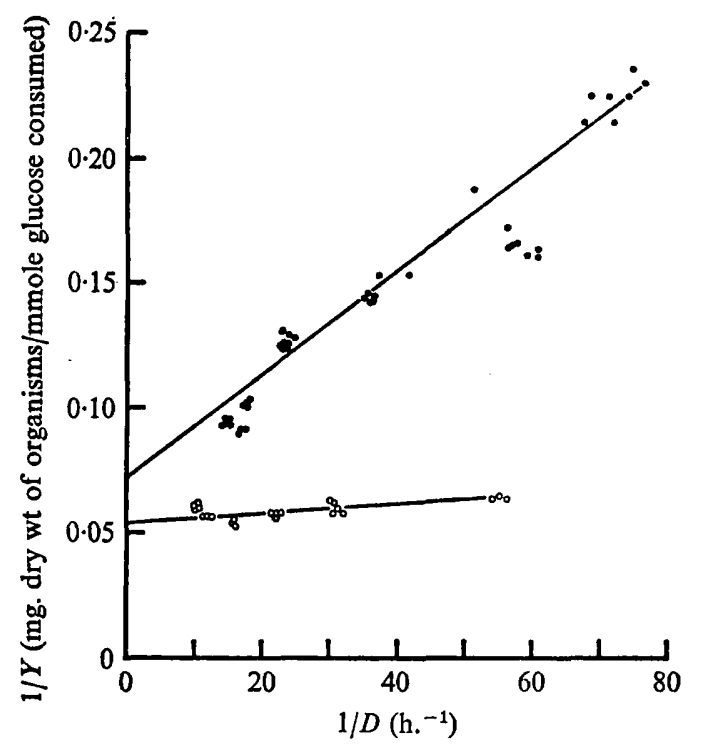

Fig. I

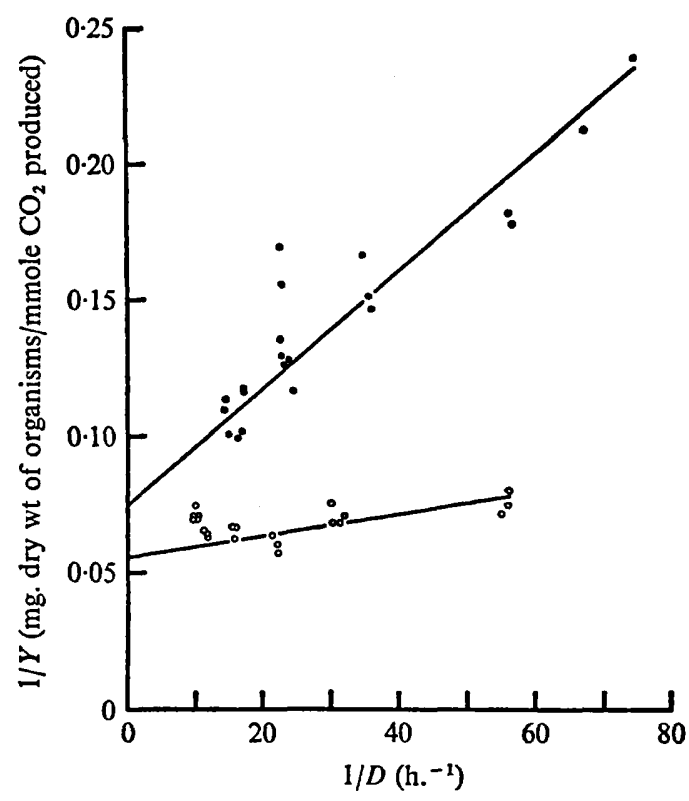

Fig. 2

Fig. I. Reciprocal plots relating yield (based on glucose consumed) to dilution rate in carbonlimited continuous cultures of a respiratory-deficient mutant of Saccharomyces cerevisiae IGC 3507. O, Data for culture with $\mathrm{I} \cdot \mathrm{O}-\mathrm{NaCl}$; $\mathrm{O}$, data for culture without $\mathrm{NaCl}$.

Fig. 2. Reciprocal plots relating yield (based on $\mathrm{CO}_{2}$ produced) to dilution rate in carbonlimited continuous cultures of a respiratory-deficient mutant of Saccharomyces cerevisiae IGC 3507 . Data for culture with $\mathrm{I} \cdot \mathrm{O} \mathrm{M}-\mathrm{NaCl} ; \mathrm{O}$, data for culture without $\mathrm{NaCl}$.

The culture grown without $\mathrm{NaCl}$ produced glycerol. Saccharomyces cerevisiae grown anaerobically produces glycerol (Nordström, I966, I968) probably due to the generation of excess $\mathrm{NADH}_{2}$ which is removed through the conversion of dihydroxyacetone phosphate to glycerol phosphate. The yield with respect to glycerol production in this culture was constant for most dilution rates studied and suggested a surplus of $\mathrm{NADH}_{2}$ directly proportional to biomass production (Fig. 3). The culture containing $\mathrm{NaCl}$ also produced glycerol. However, the presence of $\mathrm{NaCl}$ resulted in a lowering of the yield of organisms with respect to glycerol (Fig. 3). Similar results were found in 
batch culture (Table I). Respiratory-sufficient $S$. cerevisiae grown aerobically does not normally produce glycerol. Glycerol production was, however, induced when the wild-type was grown in the presence of $\mathrm{NaCl}$ (Table I). Similar results have been recorded for other yeasts (Ônishi, 1963). It would appear, then, that enhanced glycerol production under the influence of $\mathrm{NaCl}$ cannot be explained directly in terms of the maintenance of a certain intracellular $\mathrm{NAD} / \mathrm{NADH}_{2}$ ratio.

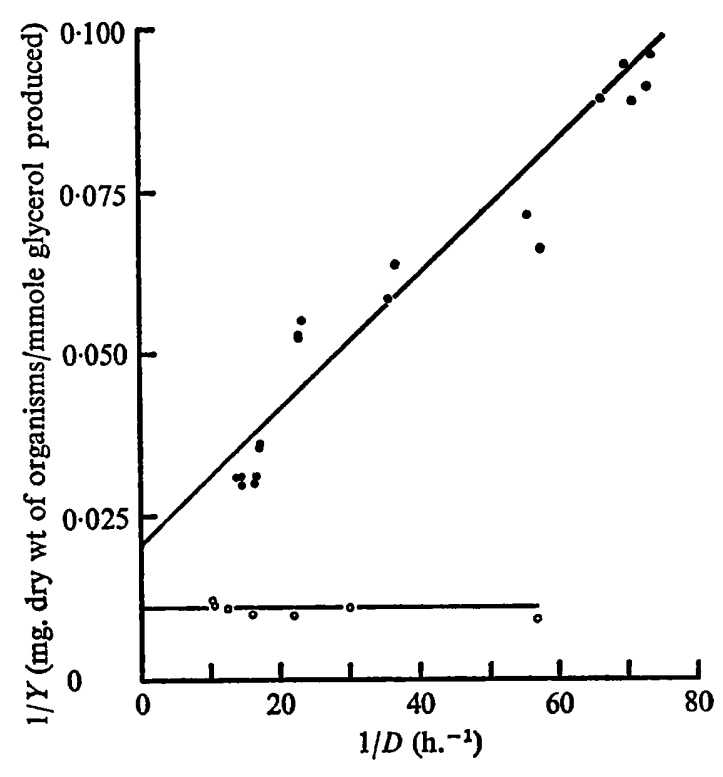

Fig 3

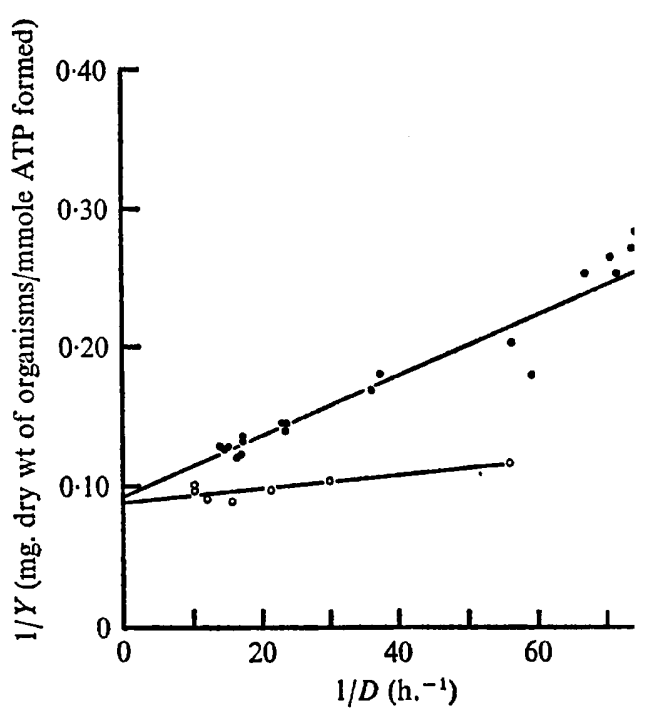

Fig. 4

Fig. 3. Reciprocal plots relating yield (based on glycerol produced) to dilution rate in carbonlimited continuous cultures of a respiratory-deficient mutant of Saccharomyces cerevisiae IGC 3507. , Data for culture with I.O M-NaCl; $\bigcirc$, data for culture without $\mathrm{NaCl}$.

Fig. 4. Reciprocal plots relating calculated yield (based on ATP formed) to dilution rate in carbon-limited continuous cultures of a respiratory-deficient mutant of Saccharomyces cerevisiae IGC 3507 . Data for culture with $1 \cdot 0 \mathrm{M}-\mathrm{NaCl}$; $\bigcirc$, data for culture without $\mathrm{NaCl}$.

Table I. Production of glycerol by wild-type and mutant strains of Saccharomyces cerevisiae IGC 3507 grown batchwise in media containing sodium chloride

\begin{tabular}{|c|c|c|c|c|c|c|c|}
\hline \multirow{3}{*}{ Strain } & \multicolumn{7}{|c|}{$\mathrm{NaCl}$ concentration in medium (M) } \\
\hline & o & 0.25 & 0.50 & 0.75 & $\mathbf{I} \cdot 00$ & $I \cdot 25$ & $1 \cdot 50$ \\
\hline & \multicolumn{7}{|c|}{ Yield (g. dry wt organisms/mole glycerol produced) } \\
\hline $\begin{array}{l}\text { Wild-type strain } \\
\text { Mutant strain }\end{array}$ & $\begin{array}{c}>100,000 \\
66\end{array}$ & $\begin{array}{c}64,000 \\
56\end{array}$ & $\begin{array}{r}850 \\
43\end{array}$ & $\begin{array}{r}330 \\
34\end{array}$ & $\begin{array}{r}140 \\
27\end{array}$ & $\begin{array}{l}89 \\
24\end{array}$ & $\begin{array}{l}55 \\
18\end{array}$ \\
\hline
\end{tabular}

Organisms grown continuously in the presence of $\mathrm{NaCl}$ showed greatly increased production of glycerol per unit of biomass formed as the dilution rate was decreased. The plot of I / $Y$ (glycerol) against I / $D$ was not linear; glycerol production is apparently not a simple function of energy metabolism and variations in $Y_{\max }$ (glycerol) may therefore be expected to occur with dilution rate. The value of $k_{\mathrm{m}}$ with respect to 
glycerol was I $\mu$ mole $/ \mathrm{mg}$./h. (Fig. 3). In the $\mathrm{NaCl}$-free culture there was no production of glycerol linked to maintenance.

Since any deviations from linearity in the plot of $\mathrm{I} / Y$ (glycerol) against $\mathrm{I} / D$ will cause deviations in the plot for yield based on glucose, and since there was production of glycerol during maintenance in the $\mathrm{NaCl}$-containing culture, a more satisfactory analysis of the results would be obtained in terms of ATP utilized for biomass production ( $\mathrm{Y}^{\mathrm{ATP}}$ ) eliminating completely the 'glycerol effect'. Fig. 4 shows a reciprocal plot for $Y^{\mathrm{ATP}}$ assuming that each mole of glucose utilized produces 2 moles of ATP, unless it is converted to glycerol when it consumes 2 moles of ATP (or I mole of ATP/mole of glycerol formed). The calculated values are probably low with respect to $Y_{\max }^{\mathrm{ATP}}$ as some glucose will certainly not enter the Embden-Meyerhof pathway but may enter biosynthetic pathways. This, however, should not affect the slope of the line as it is reasonable to assume that under carbon-limitation the partial contributions of processes leading to biomass production are not affected too greatly by growth rate. Hence an evaluation of the ATP turnover for maintenance may be obtained and was $0.52 \mu$ mole of ATP $/ \mathrm{mg}$. dry wt $/ \mathrm{h}$. for organisms grown without $\mathrm{NaCl}$, and $2.2 \mu$ moles of ATP $/ \mathrm{mg}$./h., with $\mathrm{NaCl}$. Virtually the same $\mathrm{Y}_{\max }^{\mathrm{ATP}}$ of I I mg. dry wt organisms $/ \mathrm{mmole}$ of ATP was obtained for both cultures, suggesting that the effect of $\mathrm{NaCl}$ on the ATP yield is solely due to an increased requirement of maintenance energy.

\section{Cation contents of organisms}

Organisms grown with and without $\mathrm{NaCl}$ contained the same $\mathrm{K}^{+}$content. Some penetration of $\mathrm{Na}^{+}$occurred in the yeast grown with $\mathrm{NaCl}$ (approximately O.I M intracellular $\mathrm{Na}^{+}$concentration) but an extracellular:intracelluar $\mathrm{Na}^{+}$ratio of I0: I was maintained (Table 2).

Table 2. Sodium and potassium contents of a respiratory-deficient mutant of Saccharomyces cerevisiae IGC 3507 grown in carbon-limited continuous culture

\begin{tabular}{|c|c|c|c|c|}
\hline \multirow{3}{*}{$\begin{array}{c}\text { Dilution } \\
\text { rate }\end{array}$} & \multicolumn{4}{|c|}{ Ion content (m-equiv./g. dry wt) } \\
\hline & \multicolumn{2}{|c|}{ Without $\mathrm{NaCl}$} & \multicolumn{2}{|c|}{ With $\mathrm{NaCl}(\mathrm{I} \cdot \mathrm{OM})$} \\
\hline & $\mathrm{Na}^{+}$ & $\mathbf{K}^{+}$ & $\mathrm{Na}^{+}$ & $\mathbf{K}^{+}$ \\
\hline $\begin{array}{r}<0.02 \\
0.06-0.07\end{array}$ & $0.012 \pm 0.001(2)$ & $0.58 \pm 0.07(2)$ & $\begin{array}{l}0.25 \pm 0.06(3) \\
0.29 \pm 0.05(3)\end{array}$ & $\begin{array}{l}0.67 \pm 0.06(3) \\
0.65 \pm 0.02(3)\end{array}$ \\
\hline$>0.09$ & $0.012 \pm 0.001(2)$ & $0.76 \pm 0.10(2)$ & - & -2 \\
\hline
\end{tabular}

Means \pm standard errors are quoted with the number of observations in parenthesis. Since yeast contains approximately twice its dry wt as intracellular water, the above results may be expressed as molar concentrations upon multiplication by 0.5 .

\section{Kinetics of glucose uptake}

The kinetics of glucose uptake appeared to be changed by $\mathrm{NaCl}$. The yeast is transport-limited in glucose-limited continuous culture (van Uden, 1967b) as shown by the unidirectional Michaelis-Menten kinetics of the rate of sugar uptake without $\mathrm{NaCl}$ (Fig. 5a). The culture containing $\mathrm{NaCl}$ did not show unidirectional uptake kinetics (Fig. $5 b$ ); in addition, much higher concentrations of glucose were required to maintain a particular rate of glucose uptake. 

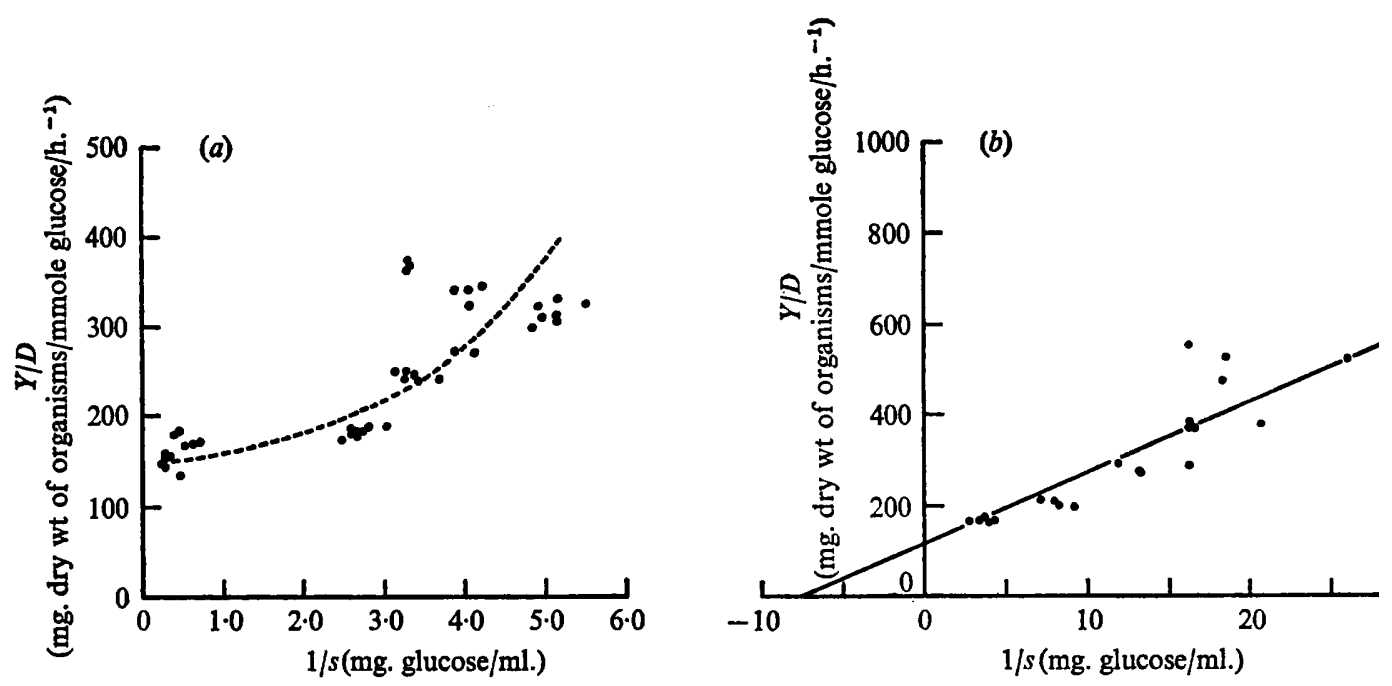

Fig. 5. Reciprocal plots relating specific glucose uptake rate to glucose concentration in carbon-limited continuous cultures of a respiratory-deficient mutant of Saccharomyces cerevisiae IGC 3507. (a) Shows data for a culture containing $1 \cdot 0 \mathrm{M}-\mathrm{NaCl} ;(b)$ for a $\mathrm{NaCl}$-free culture.

\section{DISCUSSION}

The decrease in the maximum specific growth rate in the presence of $\mathrm{NaCl}$ can be largely explained in terms of an increased requirement for energy-yielding substrate, apparently linked to maintenance, and leading to a decrease in the yield. It is probable that the increased maintenance requirement associated with growth in the presence of higher $\mathrm{NaCl}$ concentrations was concerned with maintaining an electrochemical gradient of sodium ions, the extracellular $\mathrm{Na}^{+}$concentration being ten times greater than the intracellular concentration. There is probably a passive or facilitated diffusion into the organisms (i.e. independent of metabolic energy), balanced by an active outward transport of $\mathrm{Na}^{+}$(see Stein, 1967). If the chloride ions move in both directions by either simple or facilitated diffusion then, in order to maintain equilibrium with respect to $\mathrm{Cl}^{-}$, a membrane potential, $E$, must be generated (negative to the inside) sufficient to balance the opposing chemical potential difference (Nernst equation)

$$
E=\frac{R T}{F} \ln \frac{[\mathrm{Cl}]_{0}}{[\mathrm{Cl}]_{i}}
$$

where $F$ is the Faraday, $R$ is the gas constant, $[\mathrm{Cl}]_{0}$ and $[\mathrm{Cl}]_{1}$ are the extracellular and intracellular concentrations (activities) of chloride. The sodium ions, however, will be subjected to both an adverse chemical and electrical potential gradient. The free energy change for the movement of I mole of sodium across the membrane will therefore be

$$
\Delta G_{\mathrm{Na}^{+}}=R T \ln \frac{[\mathrm{Na}]_{0}}{[\mathrm{Na}]_{1}}+E F
$$

where $[\mathrm{Na}]_{0}$ and $[\mathrm{Na}]_{1}$ are extracellular and intracellular concentrations (activities) of 
sodium. Assuming $[\mathrm{Cl}]_{1}$ and $[\mathrm{Cl}]_{0}$ to be equal to $[\mathrm{Na}]_{1}$ and $[\mathrm{Na}]_{0}$ respectively, equation (3) reduces to

$$
\Delta \mathrm{G}_{\mathrm{Na}+}=2 R T \ln \frac{[\mathrm{Na}]_{0}}{[\mathrm{Na}]_{1}} .
$$

To maintain active transport of sodium ions, a metabolic free energy decrease $\left(\Delta G_{\text {met }}\right)$ must be linked to the overall process in such a way that

$$
\Delta G_{\text {Totai }}=\left(\Delta G_{\mathrm{Na}+}+\Delta G_{\mathrm{met}}\right)<0 .
$$

In the present example, $\Delta G_{\text {Total }}$ must be sufficiently negative to assure an active $\mathrm{Na}^{+}$ efflux that will compensate for the passive influx of $\mathrm{Na}^{+}$, thus maintaining a steadystate. If the increase of ATP turnover for maintenance, in the culture with $\mathrm{NaCl}$, is concerned with $\mathrm{Na}^{+}$transport, the decrease of metabolic free energy for transport may be estimated. The difference between the $k_{\mathrm{m}}^{\mathrm{ATP}}$ of organisms grown with and without $\mathrm{NaCl}$ is $\mathrm{I} \cdot 7 \mu$ moles $\mathrm{ATP} / \mathrm{mg}$./h. Taking the standard free energy change of ATP hydrolysis as a measure, the metabolic free energy decrease linked to $\mathrm{Na}^{+}$transport would be $-5 \times 10^{-2} \mathrm{~J} / \mathrm{mg}$. organisms $/ \mathrm{h}$.

Substitution of $[\mathrm{Na}]_{0}=\mathrm{I} \cdot 0$ and $[\mathrm{Na}]_{\mathrm{i}}=0 \cdot \mathrm{I}$ into equation (4) shows that the rate of active transport of $\mathrm{Na}^{+}$out of the cell (or the diffusion rate into the cell) must be less than $5 \mu$ moles/mg. dry wt of organisms/h. (equation 5). If, further, a direct stoichiometric relationship exists between the sodium transport rate and the turnover rate of ATP, e.g. through an ATPase (see Glynn, 1968), the above result only allows two possible values, I or $2 \mathrm{Na}^{+} /$ATP molecule hydrolysed or a $\mathrm{Na}^{+}$transport rate of $\mathrm{I} \cdot 7$ or $3.4 \mu$ moles $\mathrm{Na}^{+} / \mathrm{mg}$./h. Measurement of the intial uptake rate of labelled $\mathrm{Na}^{+}$into Saccharomyces cerevisiae from $\mathrm{I} \cdot 35 \mathrm{M}-\mathrm{NaCl}$ by Norkrans \& Kylin (1969) gave a value of approximately I $\mu$ mole $\mathrm{Na}^{+} / \mathrm{mg}$./h. showing a reasonable agreement.

The present study reveals no information about the mechanism of the active transport process or whether it is linked directly to the metabolic energy of ATP. The significance of increased glycerol production is also obscure. Its production could be a result of the activation of certain enzymes on the pathway leading to glycerol by $\mathrm{NaCl}$ (Schoeffeniels, 1969); alternatively, it might be a byproduct of increased organic acid production necessary for $\mathrm{NAD} / \mathrm{NADH}_{2}$ regulation (a fall in $\mathrm{pH}$ value would be advantageous as it decreases the velocity of $\mathrm{Na}^{+}$uptake; Armstrong \& Rothstein, I964). It is, however, difficult to explain why the increased production of glycerol expressed itself primarily as a maintenance effect.

The present finding may be significant in a marine environment containing low concentrations of energy source (Duursma, I960; Vaccaro, Hicks, Jannasch \& Carey, 1968). Not only will the yield of organisms, with similar $\mathrm{Na}^{+}$requirements, be severely decreased at the low growth rates imposed but, in some cases, the concentration of assimilable carbohydrate may not be high enough to sustain growth, or to allow competition with better adapted organisms using lower concentrations for an equal growth rate (Jannasch, I968; van Uden \& Fell, I968).

I am grateful to Dr N. van Uden for helpful and critical discussions and to lic. biol. Cecília Cabçea-Silva for her technical assistance. This work was supported by a grant from the Calouste Gulbenkian Foundation, Lisbon (United Kingdom and British Commonwealth Branch). 


\section{REFERENCES}

Armstrong, W. Mc. D. \& Rothstein, A. (I964). Discrimination between alkali metal cations by yeast. I. Effect of pH on uptake. Journal of General Physiology 48, 6I-7I.

Combs, T. J., Guarneri, J. J. \& Pisano, M. A. (1968). The effect of sodium chloride on the lipid content and fatty acid composition of Candida albicans. Mycologia 6o, 1232-1239.

DuURSMA, E. F. (1960). Dissolved organic carbon, nitrogen and phosphorus in the seas. Netherlands Journal of Marine Research I, I-I48.

GLYNN, I. M. (1968). Membrane adenosine triphosphatase and cation transport. British Medical Bulletin 24, I65-169.

INGRAM, M. (1957). Micro-organisms resisting high concentrations of sugar and salts. In Microbial Ecology, p. 90. Edited by R. E. O. Williams \& C. C. Spicer. Cambridge University Press.

JANNASCH, H. W. (1968). Growth characteristics of heterotrophic bacteria in seawater. Journal of Bacteriology 95, 722-723.

NoRdSTRöm, K. (1966). Yeast growth and glycerol formation. Acta chemica scandinavica 20, I0I6I025.

NoRDSTRÖM. K. (1968). Yeast growth and glycerol formation. II. Carbon and redox balances. Journal of the Institute of Brewing 74, 429-432.

NoRKRANS, B. (I966). Studies on marine occurring yeasts: growth related to $\mathrm{pH}, \mathrm{NaCl}$ concentration and temperature. Archiv für Mikrobiologie 54, 374-392.

NoRKRANS, B. (1968). Studies on marine occurring yeasts: respiration, fermentation and salt tolerance. Archiv für Mikrobiologie 62, 358-372.

Norkrans, B. \& KyLIN, A. (1969). Regulation of the potassium to sodium ratio and of the osmotic potential in relation to salt tolerance in yeasts. Journal of Bacteriology roo, 836-845.

ONIsHI, H. (1963). Studies on osmophilic yeasts. XV. The effects of high concentrations of sodium chloride on polyalcohol production. Agricultural Biological Chemistry, Tokyo 27, 543-547.

Phaff, H. J., Mrak, E. M. \& Williams, O. B. (1952). Yeasts isolated from shrimp. Mycologia 54, $431-45 I$.

PIRT, S. J. (1965). The maintenance energy of bacteria in growing cultures. Proceedings of the Royal Society, Series B 163, 224-231.

Ross, S. S. \& MORRIS, E. O. (I962). Effect of sodium chloride on the growth of certain yeasts of marine origin. Journal of the Science of Food and Agriculture 9, 467-475.

SChoeffenIELS, E. (1969). Cellular aspects of membrane permeability. In Handbook of Molecular Cytology. Edited by A. Lima de Faria. Amsterdam: North-Holland Publishing Company.

Stern, W. D. (1967). The Movement of Molecules Across Cell Membranes, p. 23I. New York: Academic Press.

Tempest, D. W., Dicks, J. W. \& Hunter, J. R. (I966). The interrelationship between potassium, magnesium and phosphorus in potassium-limited chemostat cultures of Aerobacter aerogenes. Journal of General Microbiology 45, 135-146.

Vaccaro, R. F., Hicks, S. E., Jannasch, H. W. \& Carey, F. G. (1968). The occurrence and role of glucose in seawater. Limnology and Oceanography 13, 356-360.

VAN UDEN, N. (1967a). Transport-limited fermentation and growth of Saccharomyces cerevisiae and its competitive inhibition. Archiv für Mikrobiologie 58, I55-r68.

VAN UDEN, N. (1967b). Transport-limited growth in the chemostat and its competitive inhibition; a theoretical treatment. Archiv für Mikrobiologie 58, 145-154.

VAN UDEN, N. (1968). Yield and maintenance analysis in the chemostat; A tool for metabolic studies of growing cells. Archiv für Mikrobiologie 62, 34-40.

van UdEN, N. \& Fell, J. W. (1968). Marine yeasts. In Advances in Microbiology of the Sea, vol. I, p. I67. Edited by M. R. Droop \& E. J. Ferguson Wood. London: Academic Press.

van Uden, N \& Buckley, H. (1970). The genus Candida. In The Yeasts. Edited by J. Lodder. Amsterdam: North-Holland Publishing Company. 
van Uden, N. \& Vidal-Leiria, M. (1970). The genus Torulopsis. In The Yeasts. Edited by J. Lodder. Amsterdam; North-Holland Publishing Company.

WATson, T. G. (1969). Steady-state operation of a continuous culture at maximum growth rate by control of carbon dioxide production. Journal of General Microbiology 59, 83-89. 